\title{
JUSTIFYING THE LINDAHL SOLUTION AS AN OUTCOME OF FAIR COOPERATION
}

\author{
WOLFGANG BUCHHOLZ \\ WOLFGANG PETERS
}

CESIFO WORKING PAPER NO. 1536

CAtegory 1: Public FinanCE

SEPTEMBER 2005

An electronic version of the paper may be downloaded

- from the SSRN website:

www.SSRN.com

- from the CESifo website:

www.CESifo-group.de 


\title{
JUSTIFYING THE LINDAHL SOLUTION AS AN OUTCOME OF FAIR COOPERATION
}

\begin{abstract}
The Lindahl equilibrium is mostly motivated by a rather artificial price mechanism. Even though the analogy to a competitive market has been emphasised by Lindahl himself his approach does not directly explain the normative ideas, which are behind this concept. In the present paper we therefore show how the Lindahl equilibrium can be deduced from some simple equity axioms that in particular are related to the equal sacrifice principle and a nonenvy postulate as norms for distributional equity. Fairness among agents with different preferences is taken into account by considering their marginal willingnesses to pay as virtual prices. In this way it might also become more understandable why the Lindahl solution can be perceived as an outcome of fair cooperation.
\end{abstract}

JEL Code: C78, D63, H41.

Keywords: public goods, Lindahl equilibrium, fairness, equity.

Wolfgang Buchholz

Department of Economics

University of Regensburg

93040 Regensburg

Germany

wolfgang.buchholz@wiwi.uni-regensburg.de
Wolfgang Peters

Department of Economics

European University Viadrina

Postfach 1786

15207 Frankfurt (Oder)

Germany

peters@euv-frankfurt-o.de

A preliminary version of this paper has been presented at seminars at the Universities of Chemnitz and Linz. We thank the participants of these seminars for their helpful comments. Many thanks also to Todd Sandler who has made important suggestions to improve the paper. 


\section{Motivation}

The Lindahl equilibrium is one of the most prominent concepts in the theory of public goods that, in the context of the intensified interest in transnational public goods as combating global warming, has attained more attention in the last years ${ }^{1}$. According to Lindahl's concept every agent acts as a cost-share taker who, being confronted with an adequately chosen individualised price, wants to consume the same amount of the public good. The allocation characterised in this way is Pareto efficient and thus the Lindahl solution is quite parallel to a competitive market equilibrium for private goods. The attractiveness of Lindahl's construction mainly lies in this analogy, which is mostly used to provide the motivation for the concept $^{2}$. Based on a purely artificial price mechanism this usual justification of the Lindahl equilibrium, however, is not directly linked to the allocation problem as stated by Lindahl (1919/1958) himself: How much of a public good should be provided and how should the costs of the public good be shared among the agents such that the resulting allocation can be considered as "just" and can thus be expected as the outcome of a "free agreement" between the agents involved?

In the literature there are a few attempts to bridge this gap and to provide an alternative motivation for the Lindahl equilibrium referring to equity or fairness concepts. In Silvestre's (1984) voluntariness approach the Lindahl outcome was identified as an allocation in which no agent would prefer to get a reduction of public-good supply accompanied by a proportional reduction of its contribution to the public good. Sato (1987), by a specific construction, characterized the Lindahl solution as an envy-free allocation in which no agent would want to interchange its position with someone else. Van den Nouweland, Tijs and Wooders (2002) motivate the Lindahl solution by a consistency requirement, and in the approach of Bilodeau and Gravel (2004), Lindahlian cost sharing turns out to be a special case of a general class of cost-sharing rules that fulfil some Kantian maxim of equal treatment.

Notwithstanding these contributions it is not quite transparent what the normative underpinnings of the Lindahl solution are that should make it appealing as a potential outcome of fair cooperation. In this note we therefore want to show how in the standard public-good model with a summation technology (like in Bergstrom, Blume and Varian, 1986, and Cornes and Sandler, 1996) the Lindahl solution can be based directly on simple equity conditions the most well-known of which is the benefit principle. Following its classical interpretation, eve-

\footnotetext{
${ }^{1}$ Some prominent examples are Chichilnisky and Heal (1994), Sandler (2004) and in particular Uzawa (2003).

${ }^{2}$ For details see Atkinson and Stiglitz (1980, pp. 509-512), Myles (1995, pp. 271-277) and Cornes and Sandler (1996, pp. 201-203).
} 
ryone should pay for a public good according to his marginal willingness to pay. For each individual this means a "quid pro quo"-exchange as it is given in competitive markets for private goods. In this paper we want to show in addition that, in the case of public goods, the benefit principle can be related to equity norms concerning the distribution of public-good contributions among the parties. So, in particular, we assume that in the solution agreed upon each agent should carry the same burden for financing the public good after differences in willingness to pay have been taken into account. It turns out that this postulate for distributional equity combined with Pareto efficiency leads to the Lindahl equilibrium without invoking a Walrasian auctioneer. The relationship between equity postulates and the Lindahl equilibrium partly seems to be some kind of "common knowledge" in the theory of public goods. The aim of this paper is to make the intuition behind more explicit and thus to give a more transparent and sound normative foundation of the Lindahl solution.

\section{Axiomatic Characterisations of the Lindahl Solution}

We consider a standard public-good economy with $n$ agents. Each agent $i$ has an exogenously given income $y_{i}$. Preferences are characterized by the utility function $u_{i}\left(x_{i}, G\right)$ where $x_{i} \geq 0$ denotes agent $i$ 's private consumption and $G \geq 0$ is the provision level of a public good. All utility functions are assumed to have the usual properties: they are strict monotonously increasing in both types of consumption, twice continuously differentiable for $\left(x_{i}, G\right)>$ 0 , strictly quasi-concave, and the private as well as the public good are non-inferior. By $g_{i}=y_{i}-x_{i}$ we denote agent $i$ 's contribution to the public good, which is the part of $i$ 's income that is spent for providing the public good. By assuming a linear technology, which transforms one unit of private into one unit of public consumption, we can normalise $m r t=1$. Thus any feasible allocation fulfils

$$
G=\sum_{i=1}^{n} g_{i}
$$

which is a self-financing condition and corresponds to a balanced public budget. 
For any $\left(x_{i}, G\right)>0$ agent $i$ 's marginal rate of substitution between the public and the private good is denoted by $\pi_{i}\left(x_{i}, G\right)=\frac{\partial u_{i} / \partial G}{\partial u_{i} / \partial x_{i}}$. Or, putting it differently, $\pi_{i}\left(x_{i}, G\right)$ measures agent $i$ 's marginal willingness to pay for the public good at $\left(x_{i}, G\right)$.

Given $n$ agents with preferences represented by $\left(u_{1}, \ldots, u_{n}\right)$ and strictly positive income levels $\left(y_{1}, \ldots, y_{n}\right)$ the mechanism $L$ defines a vector of Lindahl prices $\left(p_{1}^{L}, \ldots, p_{n}^{L}\right)$ such that, if $G^{L}$ denotes public-good supply in the Lindahl equilibrium, each agent $i$ maximises utility $u_{i}\left(y_{i}-p_{i}^{L} G, G\right)$ by choosing the public-good level $G^{L}$ and then has private consumption $x_{i}^{L}=y_{i}-p_{i}^{L} G^{L}$. If we additionally assume that the indifference curves of all agents do not intersect both axes, normality implies existence and uniqueness of the Lindahl allocation $\left(x_{1}^{L}, \ldots, x_{n}^{L}, G^{L}\right)^{3}$. In contrast to $L$, let $M$ denote some general allocation mechanism which, for given preferences $\left(u_{1}, \ldots, u_{n}\right)$ and strictly positive income levels $\left(y_{1}, \ldots, y_{n}\right)$, appoints a specific allocation $\left(x_{1}^{M}, \ldots, x_{n}^{M}, G^{M}\right)$ that is self-financing according to (1): $\sum_{i=1}^{n} g_{i}^{M}=G^{M}$. Additionally, we suppose that the selected allocation is interior $\left(0<x_{i}^{M}<y_{i}\right.$ for all $i$, and $G^{M}>0$ ). This assumption characterises minimal fairness requirements, as it excludes two rather strange financing conditions for the public good. On the one hand, agent $i$ must not suffer from having no private consumption. Hence, the mechanism $M$ does not allow a full exploitation of agent $i$ through the other agents. On the other hand, each agent does not get a free lunch and thus has to bear at least a small cost share of financing the public good.

Besides feasibility, we now want to impose some additional properties which the mechanism $M$ should fulfil. As we are interested in an efficient and somehow fair mechanism, these conditions are meant to incorporate some basic normative ideas. The first axiom is the uncontroversial efficiency postulate.

Efficiency (EF): The allocation $\left(x_{1}^{M}, \ldots, x_{n}^{M}, G^{M}\right)$ is Pareto optimal.

The axiom EF implies that for the allocation picked out by $M$ the Samuelson condition holds, such that the sum of marginal rates of substitution of the $n$ agents equals the marginal rate of transformation:

\footnotetext{
${ }^{3}$ For an elementary proof of this result see Buchholz, Cornes and Peters (2005).
} 


$$
\sum_{i=1}^{n} \pi_{i}\left(x_{i}^{M}, G^{M}\right)=1
$$

The other class of axioms we are now going to formulate reflects equity considerations, which refer to agents' contributions (or cost shares) when financing the public good. To base equity directly on the individual contributions $g_{i}^{M}$ measured in units of the private good is clearly inappropriate, as this would not take different preferences for the public good into account - which does not seem fair. Spending the same amount of income for the public good means a higher subjective burden for an agent who does not receive much benefit from the public good and thus has a low willingness to pay for it ${ }^{4}$. A fair mechanism has to incorporate such concerns. To correct for the effect of different individual valuations, contributions have to be converted into commensurable equivalents before an equity maxim can reasonably be applied. This transformation is done in a standard way by applying the marginal rates of substitution of the different agents as virtual public-good prices ${ }^{5}$.

Equity may now be captured in various ways, so first by directly imposing the benefit principle $^{6}$ in its classical interpretation. As an equity maxim related to the Lindahl solution this is closest to the existing literature.

Benefit Principle (BP): Under the mechanism $M$

$$
g_{i}^{M}=\pi_{i}\left(x_{i}^{M}, G^{M}\right) G^{M}
$$

holds for all individuals.

This axiom means that every individual has to spend that share of its income for the public good, which - according to the individual's marginal willingness to pay - is equivalent

\footnotetext{
${ }^{4}$ See already Wicksell (1896/1958, p. 77) for this argument where he identified the group with small willingness to pay to the public good with the "lower class".

${ }^{5}$ For a fundamental criticism of using marginal valuations for comparing public-good contributions, however, see Brennan (1976, 1981).

${ }^{6}$ For a general discussion of the benefit principle see already Wicksell (1896/1958), Musgrave (1959, pp. 61-89) and more recently Sandler (2004, pp. 77-79), referring especially to the provision of international public goods, and Silvestre (2004, pp. 535-536).
} 
to the amount of the public good provided under $M^{7}$. In the sense of "value and countervalue", everyone pays what he gets. On competitive markets for private goods this benefit principle is automatically fulfilled which provides the basis for considering market exchange as just.

It is an important message of the present paper that BP can be deduced from other equity axioms that are related to concepts of a fair burden sharing among individuals, i.e. to distributional equity relative to the individual contributions.

Proportional Contributions (PC): Under the mechanism $M$

$$
\frac{g_{i}^{M}}{g_{j}^{M}}=\frac{\pi_{i}^{M}\left(x_{i}^{M}, G^{M}\right)}{\pi_{j}^{M}\left(x_{j}^{M}, G^{M}\right)}
$$

holds for all pairs of individuals.

This axiom means that the cost shares of the agents in financing the public good are proportional to their marginal willingness to pay $^{8}$. The higher an agent's willingness to pay of an agent, the higher is the contribution to the public good he should make if mechanism $M$ is applied. In this sense, everyone pays according to his preferences for the public good whichseems to be a fair cost-sharing rule when agents are different.

Lindahl (1919/1958, pp. 171-172) gave some algebraic treatment of the special case where the utility functions are quasi-linear, i.e. $u_{i}\left(x_{i}, G\right)=x_{i}+f_{i}(G)$. Then condition (4) requires that cost shares are proportional to the individual marginal utilities $f_{i}^{\prime}\left(G^{M}\right)$ of the public good at $G^{M}$. As for quasi-linear preferences income effects do not matter, Lindahl's example focuses on differences in individual tastes.

\footnotetext{
${ }^{7}$ Sandler (2004, p. 78) interprets the benefit principle in this way by saying that it "requires that a good's recipients pay their marginal willingness to pay (MWTP)". To Sandler this is one of the "essential principles that guide taxation at the national level and can be applied to TPGs [transnational public goods, W. B. and W. P.] at the supranational level". See also Wicksell (1896/1958, p. 75) who proposes "rejecting any public expenditure, along with its companion tax levy, which failed to render each taxpayer a service corresponding to his payment. Justice would thereby be done at least to the extent that each man received his money's worth." A critical discussion of this specific version of the benefit principle is given by Hines (2000) who also suggests another interpretation of the benefit principle. See also Kaplow (2003, esp. pp. 8-9) for a discussion of the benefit principle.

${ }^{8}$ Moulin (1995, p. 243 and pp. 286-288) interprets this condition as being some other version of the benefit principle, but doesn't take it as a starting point for characterising Lindahl equilibria. An illuminating discussion of the normative background of this cost-sharing rule is also in Moulin (1995, pp. 22-26). Moulin's (1987) own approach for making a selection among Pareto-optimal public good allocations by egalitarian-equivalent cost sharing can be interpreted as still another version of the benefit principle (see Hines, 2000).
} 
If agent $j$ has a stronger preference for the public good than agent $i$, i.e. if $f_{j}^{\prime}(G)>f_{i}^{\prime}(G)$ holds for all $G>0$, then condition (4) implies $g_{j}^{M}>g_{i}^{M}$. This conforms to an intuitive requirement of vertical equity as the agent with the higher interest in the public good has to pay more for it if $\mathbf{P C}$ is assumed.

As a contrasting example consider the case where the agents have general but identical preferences. Then vertical equity demands that the agent with the higher income makes a higher contribution to the public good, which - as a normative postulate - can also be interpreted as a variant of the venerable ability-to-pay-principle. If $\mathbf{P C}$ is assumed it follows from (4) that mechanism $M$ has this property in case of normal preferences. (See the Appendix for a precise proof.) So in a public-good economy the axiom PC implies a close relationship between two essential norms for just taxation or just burden sharing: the benefit principle on the one hand and the ability-to-pay principle on the other.

The axiom PC can also be reformulated in a somewhat different way.

Equality of Sacrifice (ES): Under the mechanism $M$

$$
\frac{g_{i}^{M}}{\pi_{i}^{M}\left(x_{i}^{M}, G^{M}\right)}=\text { const } \text {. }
$$

holds for all individuals.

This axiom means that, under the mechanism $M$, everyone bears the same burden when financing the public good. Before a comparison of individual contributions is made the monetary contribution $g_{i}^{M}$ of each agent $i$ is normalised through an adjustment for different preferences such that the individual burden is measured in public-good equivalents. This axiom implies an "equal sacrifice" in private consumption for all agents involved.

The following result shows how these axioms can be combined to justify the Lindahl solution.

Proposition: The following characterizations of the allocation mechanism $M$ are equivalent:

(i) $\quad M=L$

(ii) $\quad M$ fulfills $\mathbf{B P}$ 
(iii) $\quad M$ fulfills $\mathbf{P C}$ and $\mathbf{E F}$
(iv) $\quad M$ fulfills $\mathbf{E S}$ and $\mathbf{E F}$

Proof: (i) $\Rightarrow$ (ii): This is obvious according to the properties of $L$.

(ii) $\Rightarrow$ (i): Given $M$, let each individual $i$ be confronted with the individual public-good price $p_{i}^{M}:=\pi_{i}\left(x_{i}^{M}, G^{M}\right)$. Then, by $\mathbf{B P}$ and $g_{i}^{M}=y_{i}-x_{i}^{M}$, we have $y_{i}=x_{i}^{M}+p_{i}^{M} G^{M}$, i.e. $\left(x_{i}^{M}, G^{M}\right)$ lies on the budget line of individual $i$ given $y_{i}$ and $p_{i}^{M}$. As $p_{i}^{M}=\pi_{i}\left(x_{i}^{M}, G^{M}\right)$ the consumption bundle $\left(x_{i}^{M}, G^{M}\right)$ is utility maximising for agent $i$. Given the price vector $\left(p_{1}^{M}, \ldots, p_{n}^{M}\right)$ all price-taking agents would then choose the same public-good level $G^{M}$. As the Lindahl equilibrium is uniquely determined, then $G^{M}=G^{L}$ and $p_{i}^{M}$ must be equal to agent $i$ 's Lindahl price $p_{i}^{L}$ such that $M=L$ holds.

(ii) $\Rightarrow$ (iv): $\mathbf{E S}$ trivially follows from BP if we take $G^{M}$ as the constant on the right hand side of (5). Combining the self-financing condition (1) and BP implies

$$
G^{M}=\sum_{i=1}^{n} g_{i}^{M}=\left(\sum_{i=1}^{n} \pi_{i}\left(x_{i}^{M}, G^{M}\right)\right) G^{M}
$$

such that cancelling $G^{M}$ on both sides gives the Samuelson condition and thus EF.

(iv) $\Rightarrow$ (ii): It follows from EF (i.e. the Samuelson formula (2)), ES and the self-financing constraint (1) that for each agent $i$ the constant term on the right hand side of (5) must be identical to the public-good supply $G^{M}$ :

$$
\begin{aligned}
\frac{g_{i}^{M}}{\pi_{i}\left(x_{i}^{M}, G^{M}\right)}= & =\left(\sum_{j=1}^{n} \pi_{j}\left(x_{j}^{M}, G^{M}\right)\right) \frac{g_{i}^{M}}{\pi_{i}\left(x_{i}^{M}, G^{M}\right)} \\
& =\sum_{\mathbf{E S}}^{n} g_{j=1}^{M}=G_{(1)}^{M}=\text { const. }
\end{aligned}
$$

Thus, (5) implies (3). 
That (i) implies (ii), has already been observed by Lindahl (1919/1958 p. 173) in the special case of quasi-linear preferences and has been taken up by the subsequent literature (see Musgrave, 1959, p. 77). The converse [ (ii) $\Rightarrow$ (i) ] seems to be some folk theorem in the theory of public goods (see, e.g., Musgrave, 1985, p. 17) for which an explicit statement highlighting the normative significance of "equality in exchange", however, is hard to find" The other result stated in the Proposition [ (iv) $\Rightarrow$ (ii) ] says that the benefit principle in its standard version can, in the case of public-good allocation, also be interpreted as a consequence of a conceptually different normative judgement that focuses on a balanced burden sharing among the parties. Thus, the main message of the present paper is that there exists a close relationship between distributive justice, the traditional benefit principle, and consequently with the Lindahl concept.

Note that in contrast to the conventional characterization of the Lindahl solution Pareto optimality is not an implication but an assumption in conditions (iii) and (iv) of the Proposition. Without EF the equity axioms ES (or PC) alone would not entail the Lindahl solution. Just look at the case in which there are two completely identical agents. This symmetry implies that ES and PC are fulfilled when both agents make identical contributions. However, the Lindahl equilibrium is a distinct element within the whole set of symmetric allocations.

In the special case with two agents, condition (iv) of the Proposition can be illustrated in the standard diagram, where we depict agents' cost shares $g_{1}$ and $g_{2}$ on both axes (see Cornes and Sandler, 1996, p. 202). The $g_{1}-g_{2}$-combinations along the line $P_{1} P_{2}$ represent all Pareto optima where both agents' indifference curves touch each other. The common tangent of these indifference curves on the $P_{1} P_{2}$-line has a slope, which is measured by $\frac{\pi_{2}\left(y_{2}-g_{2}, g_{1}+g_{2}\right)}{\pi_{1}\left(y_{1}-g_{1}, g_{1}+g_{2}\right)} 10$. Then, PC together with EF defines that point $\left(g_{1}^{M}, g_{2}^{M}\right)$ on the $P_{1} P_{2}-$

\footnotetext{
${ }^{9}$ For some more detailed theoretical discussion on the relationship between the benefit principle and Lindahl equilibrium see Aaron and Mc Guire (1970).

${ }^{10}$ This is obtained by solving the identity $\frac{d g_{1}}{d G}=\frac{d g_{1}}{d g_{1}+d g_{2}}=\pi_{1}$ for $\frac{d g_{2}}{d g_{1}}=\frac{1-\pi_{1}}{\pi_{1}}=\frac{\pi_{2}}{\pi_{1}}$ where the last equality follows from the Samuelson condition.
} 
line for which the tangent to both indifference curves passes through the origin (see Figure $1)^{11}$.

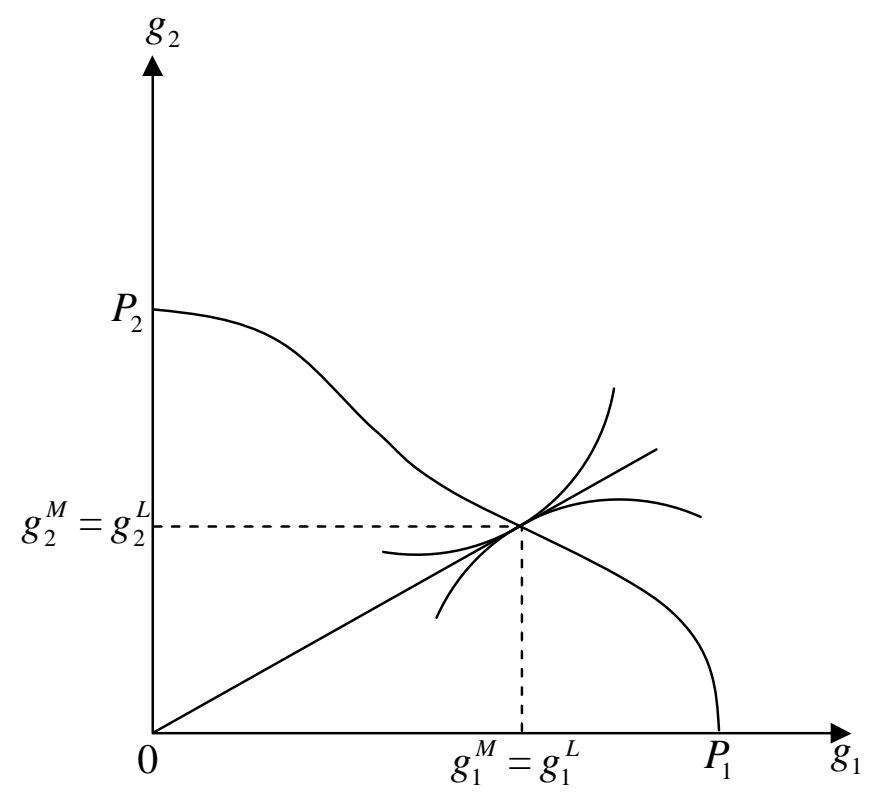

\section{Figure 1}

The axioms underlying the Proposition can slightly be weakened. So BP can be substituted by the postulate that under a mechanism $M$ the inequality

$$
g_{i}^{M} \leq \pi_{i}\left(x_{i}^{M}, G\right) G
$$

holds for each agent. This means that no one should pay more for the public good than what he receives as a public-good equivalent. If condition (7) is now combined with EF we obtain condition (3), as otherwise $G^{M}=\sum_{i=1}^{n} g_{i}^{M} \leq \sum_{i=1}^{n} \pi_{i}\left(x_{i}^{M}, G^{M}\right) G^{M}=G^{M}$ would not hold. By the Proposition, this implies $M=L$. In the special case of a linear technology as considered here, condition (7) is equivalent to Silvestre's (1984) voluntariness postulate: Define $s_{i}^{M}:=g_{i}^{M} / G^{M}$ as agent $i$ 's public-good cost share under $M$. Given (7), agent $i$ prefers $\left(x_{i}^{M}, G^{M}\right)$ over all points on the budget line $x_{i}+s_{i}^{M} G=y_{i}$ for which $G<G^{M}$. These points can be described by $\left(y_{i}-\lambda g_{i}^{M}, \lambda G^{M}\right)$ where $\lambda \in[0,1)$, such that agent $i$, starting from

\footnotetext{
${ }^{11}$ Starting from condition (iv) this graphical presentation does not make use of Lindahlian reaction curves that, however, are needed to prove existence of the Lindahl solution in the diagram.
} 
$\left(x_{i}^{M}, G^{M}\right)$, does not want to have a proportional reduction of public-good supply and its individual contribution to the public good. This, however, is just Silvestre's voluntariness axiom.

The axiom ES can be relaxed in a similar way by postulating that for any pair of agents the inequality

$$
g_{i}^{M} \leq \frac{\pi_{i}\left(x_{i}^{M}, G^{M}\right)}{\pi_{j}\left(x_{j}^{M}, G^{M}\right)} g_{j}^{M}
$$

is valid for the allocation chosen by mechanism $M$. By simply interchanging the indices $i$ and $j$ it is clear that (8) implies (5) and thus ES. Condition (8) says that no agent $i$ would prefer to have the contribution level $g_{j}^{M}$ attributed by $M$ to some other agent $j$ when $i$, being confronted with this hypothetical choice, is simultaneously forced to take differences in marginal willingness to pay into account.

With this interpretation axiom ES becomes a non-envy postulate ${ }^{12}$ : Given the allocation mechanism $M$ no one wants to change roles to get the contribution level of someone else if he simultaneously has to respect the other's preferences. In this way the parties are treated quite symmetrically. Under this fairness proviso, no one can legitimately protest against the conditions that are imposed on him in the cooperative arrangement through the mechanism $M$. This gives some reason to identify the Lindahl solution with the outcome of fair cooperation without using Lindahl's own bargaining model that is based on a rather specific and "unconvincing" construction (Silvestre, 2004, p. 528). If the parties are fairness-oriented in a strict sense they will not accept an offer that removes them to a less advantageous position relative to the other parties ${ }^{13}$. In voluntary agreements, which are reached by truly fair negotiations, there is no tolerance for unilateral privileges. Only then can we legitimately suppose equal bargaining power with the parties, which has also been a crucial element in Lindahl's $(1919 / 1958)$ approach $^{14}$.

\footnotetext{
${ }^{12}$ For another more complicated application of Varian's (1974) non-envy approach to public-good provision see Sato (1987) who uses the special and intricate notion of $L$-fairness but also uses marginal willingness to pay as the basis of comparison.

${ }^{13}$ In this spirit is also the short remark by Romer (1995, p.14): "For once interpersonal bargaining occurs, then notions of fairness may be required to describe its outcome, as a bargainer may refuse to accept an offer because he views it as unfair, a conclusion he may reach, inter alia, by making some comparison of his gain compared with his adversary's."

${ }^{14}$ So Lindahl (1919/1958, p. 169) states that if a "party has defended its own interests better than the other parties... power is not distributed evenly."
} 


\section{Conclusion}

The purpose of the Lindahl concept is to find a cooperative solution for a public-good economy that is voluntarily accepted by all agents involved. Unanimous approval over publicgood supply, however, can only be expected when the parties consider the underlying costsharing rule as equitable. Even though fair burden sharing played a central role in Lindahl's own reasoning and the ensuing discussion of his approach, maxims concerning distributional equity are not explicitly used as the starting point for a motivation of the Lindahl equilibrium. Therefore, our analysis first of all should be helpful for elucidating the Lindahl solution as a “normative concept" (see Varian, 1978, p. 200, and Inman, 1987, p. 681). Moreover, in this way the Lindahl allocation mechanism might be brought more into line with fair cooperation, which Lindahl actually had in mind ${ }^{15}$.

Considering provision of international public goods, like mitigating climate change, negotiation over public goods among independent agents has become a much more important topic in public-good theory as compared to the traditional situation in which public goods are provided by a single government. From this perspective Lindahl's thought experiment is not only of theoretical but also of practical interest as it might improve our understanding of how a bargaining solution on public goods might look like when fairness is seen as a prerequisite for an agreement.

Implementing the Lindahl solution, however, requires knowledge on the preferences of the agents involved, i.e. on their willingness to pay (see Cornes and Sandler, 1996, pp. 214221 , for a detailed discussion on this problem). From the very beginning the Lindahl concept has been plagued with this inherent problem of an efficient provision of public goods. This explains why a vast theoretical and empirical literature on preference revelation has emerged since awareness of environmental problems has increased. Concerning international public goods in particular the question arises whether the problem of asymmetric information becomes more or less serious when only a small number of governments is involved in negotiations. Discussing this quite controversial question ${ }^{16}$ is outside the framework of this paper, which concentrates on motivating the Lindahl solution as a cooperative outcome under ideal conditions usually assumed in the literature.

\footnotetext{
${ }^{15}$ See Musgrave (1959, pp. 63-77) for an illuminating review of the history of economic thought concerning the relationship between contractual arrangements, or, specifically the "contract theory of the state", and equity according to the benefit principle. In particular, Musgrave in this context refers to A. Smith's first principle of taxation.

${ }^{16}$ For arguments that might be relevant in this context see e.g., Musgrave (1959, p. 80) and Johansen (1977).
} 


\section{Appendix}

\section{Axiom PC and Ability to Pay}

In the case of identical preferences $\pi\left(x_{i}, G\right)$ denotes the common $m r s$-function of all agents. It follows from normality that $\pi\left(x_{i}, G\right)$ is increasing in $x_{i}$ given any arbitrary level of $G$ such that private consumption and the marginal willingness to pay for the public good change in the same direction (see already Kovenock and Sadka, 1981). As a consequence, the axiom PC, i.e. condition (4), implies that $g_{j}^{M}>g_{i}^{M}$ holds if and only if $x_{j}^{M}>x_{i}^{M}$. If agent $j$ has a higher income than agent $i \quad\left(y_{j}>y_{i}\right)$ this gives $g_{j}^{M}>g_{i}^{M}$ and $x_{j}^{M}>x_{i}^{M}$ since otherwise $g_{j}^{M}+x_{j}^{M}=y_{j} \leq g_{i}^{M}+x_{i}^{M}=y_{i}$ would be obtained.

As a by-product of these considerations we immediately get the result that no "rankreversal" can occur when a mechanism $M$ satisfying PC and EF (and henceforth $M=L$ ) is applied: $y_{j}>y_{i}$ implies $x_{j}^{L}>x_{i}^{L}$ and thus $u\left(x_{j}^{L}, G^{L}\right)>u\left(x_{i}^{L}, G^{L}\right)$. Thus, in the Lindahl equilibrium the agent with the higher income enjoys the higher welfare level. Therefore, an important objection raised by Brennan $(1976,1981)$ against the Lindahl solution is not valid when preferences are normal. (See also the short remark in Hines, 2000.) 


\section{References}

Aaron, H. and Mc Guire, M. (1970), Public Goods and Income Distribution, in: Econometrica $38,907-920$.

Atkinson, A. B. and Stiglitz, J. (1980), Lectures on Public Economics, Mc Graw Hill, London et al.

Bergstrom, T., Blume, L. and Varian, H. (1986), On the Private Provision of Public Goods, in: Journal of Public Economics 29, 25-49.

Bilodeau, M. and Gravel, N. (2004), Voluntary Provision of a Public Good and Individual Morality, in: Journal of Public Economics 88, 645-666.

Buchholz, W., Cornes, R. and Peters, W. (2005), Existence and Uniqueness of Lindahl Equilibria: An Elementary Proof, Discussion Paper, University of Regensburg.

Brennan, G. (1976), The Distributional Implications of Public Goods, in: Econometrica 44, 391-399.

Brennan, G. (1981), The Attribution of Public Good Benefits, in: Public Finance 36, 347-373.

Chichilnisky, G. and Heal, G. (1994), Who Should Abate Carbon Emission? An International Perspective, in: Economics Letters 44, 443-449.

Cornes, R. and Sandler, T. (1996), The Theory of Externalities, Public Goods, and Club Goods, $2^{\text {nd }}$ Edition, Cambridge University Press, Cambridge, UK et al.

Hines, J. R. Jr. (2000), What is Benefit Taxation?, in: Journal of Public Economics 75, 483492.

Inman, R. D. (1987), Markets, Governments, and the "New" Political Economy, in: A. J. Auerbach and M. Feldstein (Eds.), Handbook of Public Economics, Vol. 2, North-Holland, Amsterdam et al., Ch. 12, 647-777. 
Johansen, L. (1977), The Theory of Public Goods: Misplaced Emphasis, in: Journal of Public Economics 7, 147-152.

Kaplow, L. (2003), Public Goods and the Distribution of Income, NBER Working Paper 9842, Cambridge, MA.

Kovenock, D. and Sadka, E. (1981), Progression under the Benefit Approach to the Theory of Taxation, in: Economics Letters 8, 95-99.

Lindahl, E. (1919/1958), Die Gerechtigkeit der Besteuerung. Eine Analyse der Steuerprinzipien auf der Grundlage der Grenznutzentheorie, Håkan Ohlssons Buchdruckerei, Lund, partially translated as "Just Taxation: A Positive Solution", in: R. A. Musgrave and A. T. Peacock, Classics in the Theory of Public Finance, St. Martin's Press, New York, 168-176.

Moulin, H. (1987), Egalitarian-Equivalent Cost Sharing of a Public Good, in: Econometrica 55, 963-976.

Moulin, H. (1995), Cooperative Microeconomics. A Game-Theoretic Introduction, Princeton University Press, Princeton, NJ.

Musgrave, R. A. (1959), The Theory of Public Finance, Mc Graw-Hill, New York.

Musgrave, R. A. (1985), A Brief History of Fiscal Doctrine, in: A. J. Auerbach and M. Feldstein (Eds.), Handbook of Public Economics, Vol. 1, Amsterdam et al., Ch. 1, 1-59.

Myles, G. (1995), Public Economics, Cambridge University Press, Cambridge, UK et al.

Romer, J. E. (1995), Theories of Distributive Justice, Harvard University Press, Cambridge, MA, and London, UK.

Sandler, T. (2004), Global Collective Action, Cambridge University Press, Cambridge, UK. 
Sato, T. (1987), Equity, Fairness and Lindahl Equilibria, in: Journal of Public Economics 33, 261-271.

Silvestre, J. (1984), Voluntariness and Efficiency in the Provision of Public Goods, in: Journal of Public Economics 24, 257-270.

Silvestre, J. (2004), Wicksell, Lindahl and the Theory of Public Goods, in: Scandinavian Journal of Economics 105, 527-553.

Uzawa, H. (2003), Economic Theory and Global Warming, Cambridge University Press, Cambridge, UK.

Van den Nouweland, A., Tijs, S. and Wooders, M. (2002), Axiomatization of Ratio Equilibria in Public Good Economies, in: Social Choice and Welfare 19, 627-636.

Varian, H. (1974), Equity, Envy and Efficiency, in: Journal of Economic Theory 9, 63-91.

Varian, H. (1978), Microeconomic Analysis, $1^{\text {st }}$ Edition, W.W. Norton, New York.

Wicksell, K. (1896/1958), Ein neues Prinzip der gerechten Besteuerung, Finanztheoretische Untersuchungen, Gustav Fischer, Jena, partially translated as "A New Principle of Just Taxation", in: R. A. Musgrave and A. T. Peacock, Classics in the Theory of Public Finance, St. Martin's Press, New York, 72-118. 


\section{CESifo Working Paper Series}

(for full list see www.cesifo-group.de)

1473 Kai A. Konrad, Silent Interests and All-Pay Auctions, May 2005

1474 Ingo Vogelsang, Electricity Transmission Pricing and Performance-Based Regulation, May 2005

1475 Spiros Bougheas and Raymond Riezman, Trade and the Distribution of Human Capital, June 2005

1476 Vesa Kanniainen, Seppo Kari and Jouko Ylä-Liedenpohja, The Start-Up and Growth Stages in Enterprise Formation: The "New View" of Dividend Taxation Reconsidered, June 2005

1477 M. Hashem Pesaran, L. Vanessa Smith and Ron P. Smith, What if the UK had Joined the Euro in 1999? An Empirical Evaluation Using a Global VAR, June 2005

1478 Chang Woon Nam and Doina Maria Radulescu, Effects of Corporate Tax Reforms on SMEs' Investment Decisions under the Particular Consideration of Inflation, June 2005

1479 Panos Hatzipanayotou, Sajal Lahiri and Michael S. Michael, Globalization, CrossBorder Pollution and Welfare, June 2005

1480 John Whalley, Pitfalls in the Use of Ad valorem Equivalent Representations of the Trade Impacts of Domestic Policies, June 2005

1481 Edward B. Barbier and Michael Rauscher, Trade and Development in a Labor Surplus Economy, June 2005

1482 Harrie A. A. Verbon and Cees A. Withagen, Tradable Emission Permits in a Federal System, June 2005

1483 Hendrik Hakenes and Andreas Irmen, On the Long-Run Evolution of Technological Knowledge, June 2005

1484 Nicolas Schmitt and Antoine Soubeyran, A Simple Model of Brain Circulation, June 2005

1485 Carsten Hefeker, Uncertainty, Wage Setting and Decision Making in a Monetary Union, June 2005

1486 Ondřej Schneider and Jan Zápal, Fiscal Policy in New EU Member States - Go East, Prudent Man!, June 2005

1487 Christian Schultz, Virtual Capacity and Competition, June 2005 
1488 Yvan Lengwiler and Elmar Wolfstetter, Bid Rigging - An Analysis of Corruption in Auctions, June 2005

1489 Johannes Becker and Clemens Fuest, Does Germany Collect Revenue from Taxing Capital Income?, June 2005

1490 Axel Dreher and Panu Poutvaara, Student Flows and Migration: An Empirical Analysis, June 2005

1491 Bernd Huber and Marco Runkel, Interregional Redistribution and Budget Institutions under Asymmetric Information, June 2005

1492 Guido Tabellini, Culture and Institutions: Economic Development in the Regions of Europe, July 2005

1493 Kurt R. Brekke and Michael Kuhn, Direct to Consumer Advertising in Pharmaceutical Markets, July 2005

1494 Martín Gonzalez-Eiras and Dirk Niepelt, Sustaining Social Security, July 2005

1495 Alfons J. Weichenrieder, (Why) Do we need Corporate Taxation?, July 2005

1496 Paolo M. Panteghini, S-Based Taxation under Default Risk, July 2005

1497 Panos Hatzipanayotou and Michael S. Michael, Migration, Tied Foreign Aid and the Welfare State, July 2005

1498 Agata Antkiewicz and John Whalley, BRICSAM and the Non-WTO, July 2005

1499 Petr Hedbávný, Ondřej Schneider and Jan Zápal, A Fiscal Rule that has Teeth: A Suggestion for a 'Fiscal Sustainability Council' underpinned by the Financial Markets, July 2005

1500 J. Atsu Amegashie and Marco Runkel, Sabotaging Potential Rivals, July 2005

1501 Heikki Oksanen, Actuarial Neutrality across Generations Applied to Public Pensions under Population Ageing: Effects on Government Finances and National Saving, July 2005

1502 Xenia Matschke, Costly Revenue-Raising and the Case for Favoring Import-Competing Industries, July 2005

1503 Horst Raff and Nicolas Schmitt, Why Parallel Trade may Raise Producers Profits, July 2005

1504 Alberto Bisin and Piero Gottardi, Efficient Competitive Equilibria with Adverse Selection, July 2005

1505 Peter A. Zadrozny, Necessary and Sufficient Restrictions for Existence of a Unique Fourth Moment of a Univariate GARCH(p,q) Process, July 2005 
1506 Rainer Niemann and Corinna Treisch, Group Taxation, Asymmetric Taxation and Cross-Border Investment Incentives in Austria, July 2005

1507 Thomas Christiaans, Thomas Eichner and Ruediger Pethig, Optimal Pest Control in Agriculture, July 2005

1508 Biswa N. Bhattacharyay and Prabir De, Promotion of Trade and Investments between China and India: The Case of Southwest China and East and Northeast India, July 2005

1509 Jean Hindriks and Ben Lockwood, Decentralization and Electoral Accountability: Incentives, Separation, and Voter Welfare, July 2005

1510 Michelle R. Garfinkel, Stergios Skaperdas and Constantinos Syropoulos, Globalization and Domestic Conflict, July 2005

1511 Jesús Crespo-Cuaresma, Balázs Égert and Ronald MacDonald, Non-Linear Exchange Rate Dynamics in Target Zones: A Bumpy Road towards a Honeymoon - Some Evidence from the ERM, ERM2 and Selected New EU Member States, July 2005

1512 David S. Evans and Michael Salinger, Curing Sinus Headaches and Tying Law: An Empirical Analysis of Bundling Decongestants and Pain Relievers, August 2005

1513 Christian Keuschnigg and Martin D. Dietz, A Growth Oriented Dual Income Tax, July 2005

1514 Fahad Khalil, David Martimort and Bruno Parigi, Monitoring a Common Agent: Implications for Financial Contracting, August 2005

1515 Volker Grossmann and Panu Poutvaara, Pareto-Improving Bequest Taxation, August 2005

1516 Lars P. Feld and Emmanuelle Reulier, Strategic Tax Competition in Switzerland: Evidence from a Panel of the Swiss Cantons, August 2005

1517 Kira Boerner and Silke Uebelmesser, Migration and the Welfare State: The Economic Power of the Non-Voter?, August 2005

1518 Gabriela Schütz, Heinrich W. Ursprung and Ludger Wößmann, Education Policy and Equality of Opportunity, August 2005

1519 David S. Evans and Michael A. Salinger, Curing Sinus Headaches and Tying Law: An Empirical Analysis of Bundling Decongestants and Pain Relievers, August 2005

1520 Michel Beine, Paul De Grauwe and Marianna Grimaldi, The Impact of FX Central Bank Intervention in a Noise Trading Framework, August 2005

1521 Volker Meier and Matthias Wrede, Pension, Fertility, and Education, August 2005

1522 Saku Aura and Thomas Davidoff, Optimal Commodity Taxation when Land and Structures must be Taxed at the Same Rate, August 2005 
1523 Andreas Haufler and Søren Bo Nielsen, Merger Policy to Promote 'Global Players'? A Simple Model, August 2005

1524 Frederick van der Ploeg, The Making of Cultural Policy: A European Perspective, August 2005

1525 Alexander Kemnitz, Can Immigrant Employment Alleviate the Demographic Burden? The Role of Union Centralization, August 2005

1526 Baoline Chen and Peter A. Zadrozny, Estimated U.S. Manufacturing Production Capital and Technology Based on an Estimated Dynamic Economic Model, August 2005

1527 Marcel Gérard, Multijurisdictional Firms and Governments' Strategies under Alternative Tax Designs, August 2005

1528 Joerg Breitscheidel and Hans Gersbach, Self-Financing Environmental Mechanisms, August 2005

1529 Giorgio Fazio, Ronald MacDonald and Jacques Mélitz, Trade Costs, Trade Balances and Current Accounts: An Application of Gravity to Multilateral Trade, August 2005

1530 Thomas Christiaans, Thomas Eichner and Ruediger Pethig, A Micro-Level 'Consumer Approach' to Species Population Dynamics, August 2005

1531 Samuel Hanson, M. Hashem Pesaran and Til Schuermann, Firm Heterogeneity and Credit Risk Diversification, August 2005

1532 Mark Mink and Jakob de Haan, Has the Stability and Growth Pact Impeded Political Budget Cycles in the European Union?, September 2005

1533 Roberta Colavecchio, Declan Curran and Michael Funke, Drifting Together or Falling Apart? The Empirics of Regional Economic Growth in Post-Unification Germany, September 2005

1534 Kai A. Konrad and Stergios Skaperdas, Succession Rules and Leadership Rents, September 2005

1535 Robert Dur and Amihai Glazer, The Desire for Impact, September 2005

1536 Wolfgang Buchholz and Wolfgang Peters, Justifying the Lindahl Solution as an Outcome of Fair Cooperation, September 2005 